\title{
The impact of DC bias on electrical tree growth characteristics in epoxy resin samples
}

DOI:

10.1109/CEIDP.2015.7352082

Link to publication record in Manchester Research Explorer

\section{Citation for published version (APA):}

Iddrissu, I., \& Rowland, S. M. (2015). The impact of DC bias on electrical tree growth characteristics in epoxy resin samples. In host publication (pp. 876-879). IEEE. https://doi.org/10.1109/CEIDP.2015.7352082

\section{Published in:}

host publication

\section{Citing this paper}

Please note that where the full-text provided on Manchester Research Explorer is the Author Accepted Manuscript or Proof version this may differ from the final Published version. If citing, it is advised that you check and use the publisher's definitive version.

\section{General rights}

Copyright and moral rights for the publications made accessible in the Research Explorer are retained by the authors and/or other copyright owners and it is a condition of accessing publications that users recognise and abide by the legal requirements associated with these rights.

\section{Takedown policy}

If you believe that this document breaches copyright please refer to the University of Manchester's Takedown Procedures [http://man.ac.uk/04Y6Bo] or contact uml.scholarlycommunications@manchester.ac.uk providing relevant details, so we can investigate your claim.

\section{OPEN ACCESS}


This is the accepted manuscript, which has been accepted by IEEE for publication (C) 2015 . Personal use of this material is permitted. Permission from IEEE must be obtained for all other uses, in any current or future media, including reprinting/republishing this material for advertising or promotional purposes, creating new collective works, for resale or redistribution to servers or lists, or reuse of any copyrighted component of this work in other works. The full reference is:

\section{'The impact of DC bias on electrical tree growth characteristics in epoxy resin samples'}

I. Iddrissu and S. M. Rowland

IEEE Conference on Electrical Insulation and Dielectric Phenomena, pp. 876-879, 2015

DOI: $\underline{\text { 10.1109/CEIDP.2015.7352082 }}$ 


\title{
The Impact of DC Bias on Electrical Tree Growth Characteristics in Epoxy Resin Samples
}

\author{
I. Iddrissu and S. M. Rowland \\ The University of Manchester, School of Electrical and Electronic Engineering, \\ Manchester, M13 9PL, United Kingdom. \\ *E-mail: ibrahim.iddrissu@postgrad.manchester.ac.uk
}

\begin{abstract}
The effect of DC bias on electrical tree growth characteristics in epoxy resin samples is investigated, using three waveforms types: AC, AC with positive DC bias, and AC with negative DC bias. Point-to-plane samples were used. AC tests resulted in $62 \%$ and $48 \%$ longer average time to breakdown than positive and negative DC biased tests respectively. The negative DC bias test had $14 \%$ longer average time to breakdown than positive DC bias test. It is suggested that this is due to space charge injection modifying the field at the tree tip. 4 stages of distinct tree growth are identified in AC tests compared to 3 stages in DC bias tests. In particular, the phenomena of trees growing in the 'reverse direction' (from the planar to the point electrode) observed in the latter stages of $\mathrm{AC}$ tests, is not seen in the DC tests reported here. This is thought to be due to the peak field magnitudes involved in each case.
\end{abstract}

Keywords-Electrical treeing, Space Charge, AC, DC-bias

\section{INTRODUCTION}

Growth of an electrical tree in solid polymeric insulating material is evidence of a long term, irreversible path to failure [1]. Treeing resistance, in polymeric insulating materials for HV systems are thus widely investigated [2]. Published work in this area of research shows that higher voltages are required for an electrical tree to be initiated under DC as compared to under AC fields [3]. However, experiments using polarity reversal and impulses on DC insulation shows some materials have a vulnerability to space charge injection/accumulation and subsequent electrical treeing [4-5].

Increase in power demand and integration of renewable energy sources in the existing grid, has accelerated installation of HVDC power transmission projects around the world [6]. HVDC transmission is the preferred technology for bulk power transfer over long distances due to its economic advantages, and HVDC technologies are still being developed. Converters are required at both sides of HVDC links, and the proven technology for this is the traditional line commutated converters (LCC). LCC require voltage polarity reversal to change power flow direction, and this presents a threat to the insulation if not well managed due to space charge injection [7]. Recent voltage source converter (VSC) technology eliminates the need to reverse voltage polarity to achieve reversed power flow direction [8], but VSC technology presently has a limited voltage rating of up to $\pm 500 \mathrm{kV}$ [8] compared to LCC which is available at voltage ratings up to $\pm 800 \mathrm{kV}$. However, both converter types require extensive, and costly, filtering of harmonics. As a result, the impact of harmonics on the reliability of DC insulation requires investigation. In particular, there is potential financial

Engineering and Physicals Science Research Council UK: Top \& Tail Transformation grant, EP/1031707/1 (http://www.topandtail.org.uk) advantage if harmonics can be allowed on a network, with no consequential reduction in reliability.

Preliminary investigations in our laboratory reveal that superimposing $10 \mathrm{kV} / 50 \mathrm{~Hz}$ peak ac ripple on a $30 \mathrm{kV}$ DC source can readily initiate electrical tree in an epoxy resin sample. However, with $30 \mathrm{kV}$ DC only no tree was observed. This observation suggests that, if noise of say $10 \mathrm{kV}$ (only $2 \%$ of $500 \mathrm{kV}$ ) magnitude is realized on a $500 \mathrm{kV}$ DC link for example, its reliability may be compromised.

In this paper, preliminary results of a study on the effect of DC bias on electrical tree growth characteristics in epoxy resin samples, using point-to-plane samples are investigated. The results show that different mechanisms of electrical tree growth are seen under $\mathrm{AC}$ with and without $\mathrm{DC}$ bias.

\section{EXPERIMENTAL}

\section{A. Sample preparation}

Fig. 1 shows the sample electrode configuration for this study. To simulate a structural defect generating high divergent fields in the epoxy resin block, a point-to-plane configuration method of sample preparation was used [9]. The samples were prepared from a low viscosity epoxy resin Araldite ${ }^{\circledR}$ LY 5052 and the corresponding hardener Aradur ${ }^{\circledR}$ HY 5052 both supplied by Huntsman.

The required volume of the resin/hardener system with mixing ratio 100:38 (parts by weight) was hand-mixed for about a minute followed by magnetic stirring for 5 minutes. The mixture was degassed in a vacuum chamber at room temperature for 60 minutes and then poured into a hollow acrylic cube. The mixture is allowed to cure at room temperature for 24 hours, followed by a further 4 hours at $100^{\circ} \mathrm{C}$. Ogura needles of $1 \mathrm{~mm}$ diameter and $3 \mu \mathrm{m}$ tip radius were used as the $\mathrm{HV}$ voltage electrode with gap distance of $(1.9 \pm 0.1) \mathrm{mm}$. The 'plane' surfaces of the samples were metallised with aluminum by vacuum evaporation to ensure
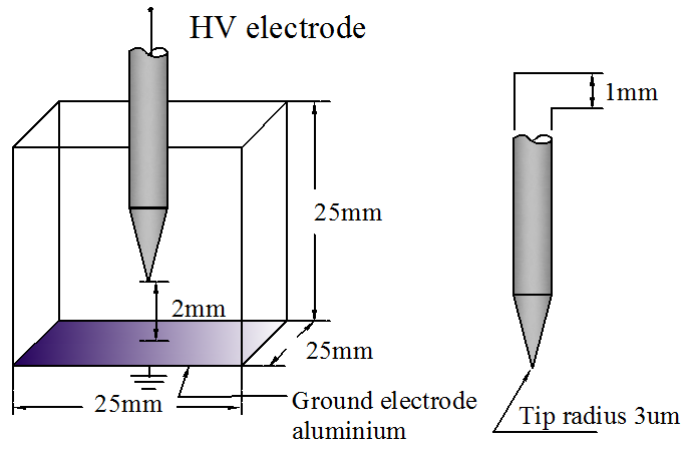

Fig. 1: Point to plane sample configuration 
good contact with the ground electrode. In total, 36 samples were fabricated as described above for this study.

\section{B. Experimental set-up and test procedure}

Fig. 2 shows the experimental set-up, which consists of two main parts. The part enclosed in the solid line is the low voltage generation and monitoring side. This part is equipped with an oscilloscope, a pre-amplifier and a purpose built PC which integrates an arbitrary waveform generator (AWG-PCI 5421) and a waveform editor, both supplied by National Instruments. Also the PC is loaded with soft front panel and common vision blox software(s), which allow flexible control of both the HV amplifier and the image-grabbing capability of the CCD camera. The equipment enclosed by the dotted line, is in an HV interlocked cage and consists of a Trek HV amplifier ( 0 to $\pm 30 \mathrm{kV}$ peak), the test cell, and a Manta monochrome progressive scan CCD camera with resolution; $2452(\mathrm{~W}) \times 2056(\mathrm{H})$. A DC-powered light source is used to eliminate image flickering during image acquisition. The experiment is performed in two stages; a quick tree-initiation process and propagation. The quick initiation is employed in order to ensure all samples have a common tree inception process which results in the shortest possible tree initiated in them. In this way, the time to breakdown from the propagation stage can be equitably compared after initiation in all tests.

Stage 1: Quick initiation: In this stage of the experiment, the CCD camera is set to capture an image every second and is fitted with a c-mount macro lens of $8 \mathrm{x}$ magnification with maximum field of view $1(\mathrm{~W}) \times 0.8(\mathrm{H}) \mathrm{mm}$, to detect and capture the shortest possible tree image after voltage application. Immediately an initial tree image is detected, the experiment is stopped and the sample replaced with new sample. All the 36 samples fabricated for this study were initiated in this manner with an unbiased AC voltage (between 12 and 16) $\mathrm{kVrms}$, and 30 samples with tree lengths not longer than $50 \mu \mathrm{m}$, called hereafter the 'initial tree', were then used for the second stage of the experiment.

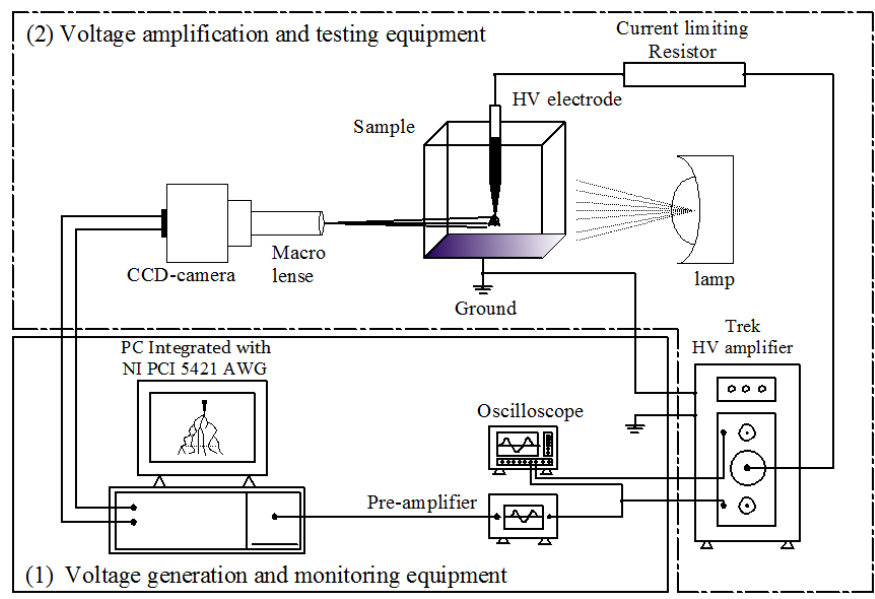

Fig. 2: Experimental set-up. Equipment in area (2) is within an interlocked high voltage enclosure
Stage 2: Propagation: In this stage, the 30 samples with their 'initial trees' were randomly divided into 3 groups of 10 samples. Each group was subjected to one of the following three voltage forms, shown in Fig. 3 and characterised in Table 1.

a. $\quad \mathrm{AC}$ test at $15 \mathrm{kV}$ peak

b. $\mathrm{AC}$ at $15 \mathrm{kV}$ peak with $+15 \mathrm{kV}$ DC bias

c. $\mathrm{AC}$ at $15 \mathrm{kV}$ peak with $-15 \mathrm{kV}$ DC bias

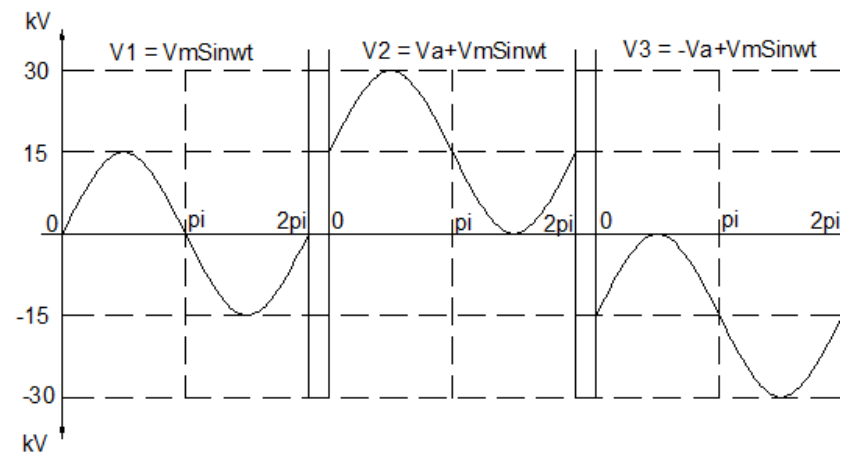

Fig. 3: Waveforms used for this study

TABLE 1: TEST VOLTAGES AND GEOMETRICAL FIELD*

\begin{tabular}{|c|c|c|c|c|}
\hline \multirow{2}{*}{$\begin{array}{c}\text { Test type and } \\
\text { calculated } \\
\text { voltages and } \\
\text { E-field }\end{array}$} & \multicolumn{4}{|c|}{ Point radius $=3$ um and Gap distance $=2 \mathrm{~mm}$} \\
\cline { 2 - 5 } & $\begin{array}{c}\mathrm{Vpk} \\
(\mathrm{kV})\end{array}$ & $\begin{array}{c}\text { Vrms } \\
(\mathrm{kV})\end{array}$ & $\begin{array}{c}\text { Eav }=\mathrm{V} / \mathrm{d} \\
(\mathrm{kV} / \mathrm{mm})\end{array}$ & $\begin{array}{c}\text { Etip }= \\
2 \mathrm{~V} / \mathrm{ln}[(1+4 \mathrm{~d} / \mathrm{r})] \\
(\mathrm{kV} / \mathrm{mm})\end{array}$ \\
\hline $\mathrm{AC}$ & 15 & 10.6 & 5.3 & 895.9 \\
\hline$+/-\mathrm{DC}+\mathrm{AC}$ & 30 & 18.4 & 9.2 & 1555 \\
\hline
\end{tabular}

*these fields are not those expected at the needle tip, but are those associated with the geometry only.

At this stage of the experiment, the CCD camera is fitted with a c-mount telecentric lens with $6(\mathrm{~W}) \times 5(\mathrm{H}) \mathrm{mm}$ dimensions of field of view. This allows the whole tree length from the initiation stage until breakdown ensued to be captured. Tests were performed in silicone oil to prevent flashover. Prior to testing the silicone oil is dried at $85^{\circ} \mathrm{C}$ for $24 \mathrm{hrs}$ and allowed to cool to room temperature under vacuum. Samples were kept under controlled humidity conditions in desiccator prior to testing, and between tree initiation and later growth tests.

In each test, the samples are continuously stressed with one of the voltage forms shown in Fig. 3 and images are taken either at 1 or 60 second intervals (depending which stage they are in) until breakdown occurred.

\section{RESULTS}

This section discusses the time to breakdown and tree growth characteristics from the three test types. Three particular samples with similar times to breakdown (i.e. 70, 77 and 81 minutes) are considered in detail, to compare and contrast typical differences observed in all of the samples tested from the three test types. These differences relate to growth characteristics and differences in the tree growth features. 


\section{A. Time to breakdown:}

Fig. 4 shows the time to breakdown from the three test types. Under the AC test regime, 3 of the samples did not breakdown: two after $12 \mathrm{hrs}$, and one after $4 \mathrm{hrs}$ of voltage application. The experiment was stopped for these samples due to the extensive damage suffered by the samples which almost turned the $2 \mathrm{~mm}$ gap into semi-carbonised material. The plot of the remaining samples shows that time to breakdown for an AC test is more widely distributed as compared to that of the positive and negative DC biased tests. The average time to breakdown under an $\mathrm{AC}$ test is 143 minutes; whereas under positive and negative DC bias tests are 54 and 78 minutes respectively. The difference in time to breakdown between $\mathrm{AC}$ and positive $\mathrm{DC}$ bias test is $62 \%$ and between $\mathrm{AC}$ and negative DC bias test is $48 \%$. The difference between positive and negative DC biased test is a reduction of $14 \%$. The possible explanations for the significant difference between pure AC and the DC biased tests is the substantially higher fields under DC bias tests compared to that under AC. However the absolute field of DC bias itself does not explain the difference since it is known that a $30 \mathrm{kV}$ DC field (with high power quality) will not grow an electric tree. However, the $14 \%$ difference between positive and negative DC bias test is probably associated with space charge moderating the field at the electrode vicinity under negative bias more than under positive bias test [9-10].

\section{B. Electrical tree growth characteristics.}

Fig. 5 shows the plots of tree growth rate characteristics of the selected three samples for the three test regimes. The shape of the plots show progressive growth characteristics in all three test types as compared to the traditional growth characteristics described in [11], which consists of three distinct stages; the inception stage, the propagation (fast and slow growth) stages and the runaway stage. But the "lying S". shape [12] obtained from the plots is a common observation on experimental tree growth characteristics found in the literature. The results shown in Fig. 5 should not be taken to show that trees grow at the same rate on average under the different voltage regimes. Fig. 4 shows this is not the case. But Fig. 5 does suggest that in the case of individual trees which lead to failures in the same times under the different stresses, they have the same changes to their growth rates during the entire process.

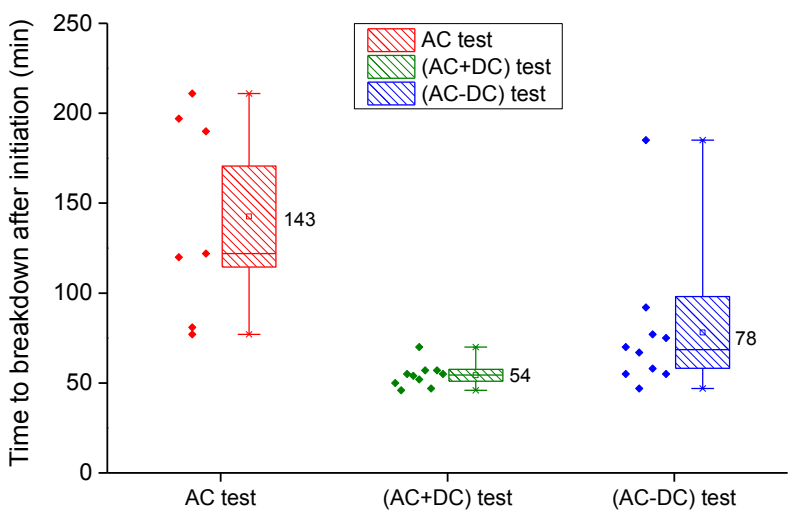

Fig. 4: Time to breakdown plots for the three test types

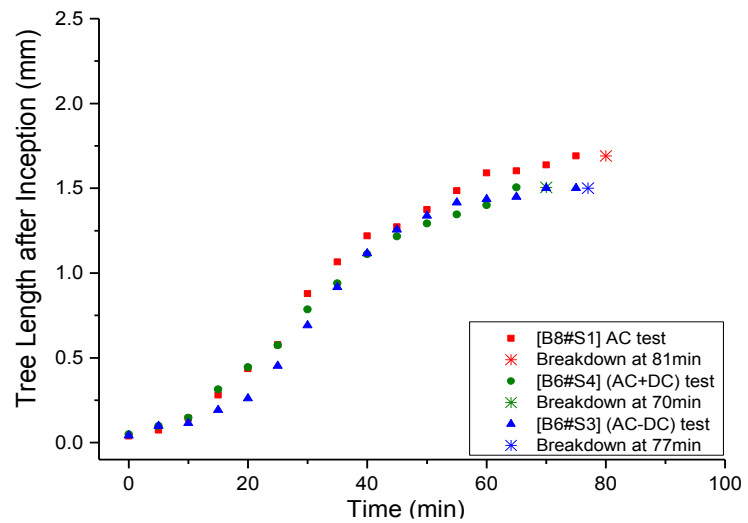

Fig. 5: Comparison of growth rate plot of three samples from the three test types after initiation

The images shown in Fig. 6 reveal four stages of growth propagation herein defined as:

1. Thick initial growth stage; characterized by dark, wide tree channels immediately in the vicinity of the point electrode. This is an extension of the initial tree, formed after the initiation stage and grows for up to about 10 minutes of voltage application, but is not necessarily fast growth.

2. Fine tree growth stage; marked by spreading of fine tree channels growing the visible aspect of the tree in both length and width, during 10 to 50 minutes of voltage application.

3. Thickening of the fine tree channels stage; characterized by darkening and widening of the fine channels on approaching the ground electrode or touching the ground electrode, shown by images at 70 minutes in Fig. 6.

4. Reverse tree growth stage. This stage is characterized by a tree growing in the opposite direction from the ground electrode towards the HV electrode. This characteristic is observed only under AC tests but was seen on all samples tested.

The 'reverse tree' seen in AC tests can apparently grow independently of the existing fine channels, and grows from the ground electrode toward the needle.

Stages 3 and 4 can both lead directly to breakdown, depending on the magnitude of the applied voltage as shown in Fig. 6.

\section{DISCUSION}

From the plots of Fig. 4 and images from Fig. 6, the differences between $\mathrm{AC}$ tests and $\mathrm{AC}$ with $\mathrm{DC}$ bias tests can be clearly seen. It is demonstrated that AC tests go through 4 stages of propagation before breakdown occurs, while in the $\mathrm{AC}$ with DC bias tests, only 3 stages are observed for both positive and negative $\mathrm{DC}$ bias. 


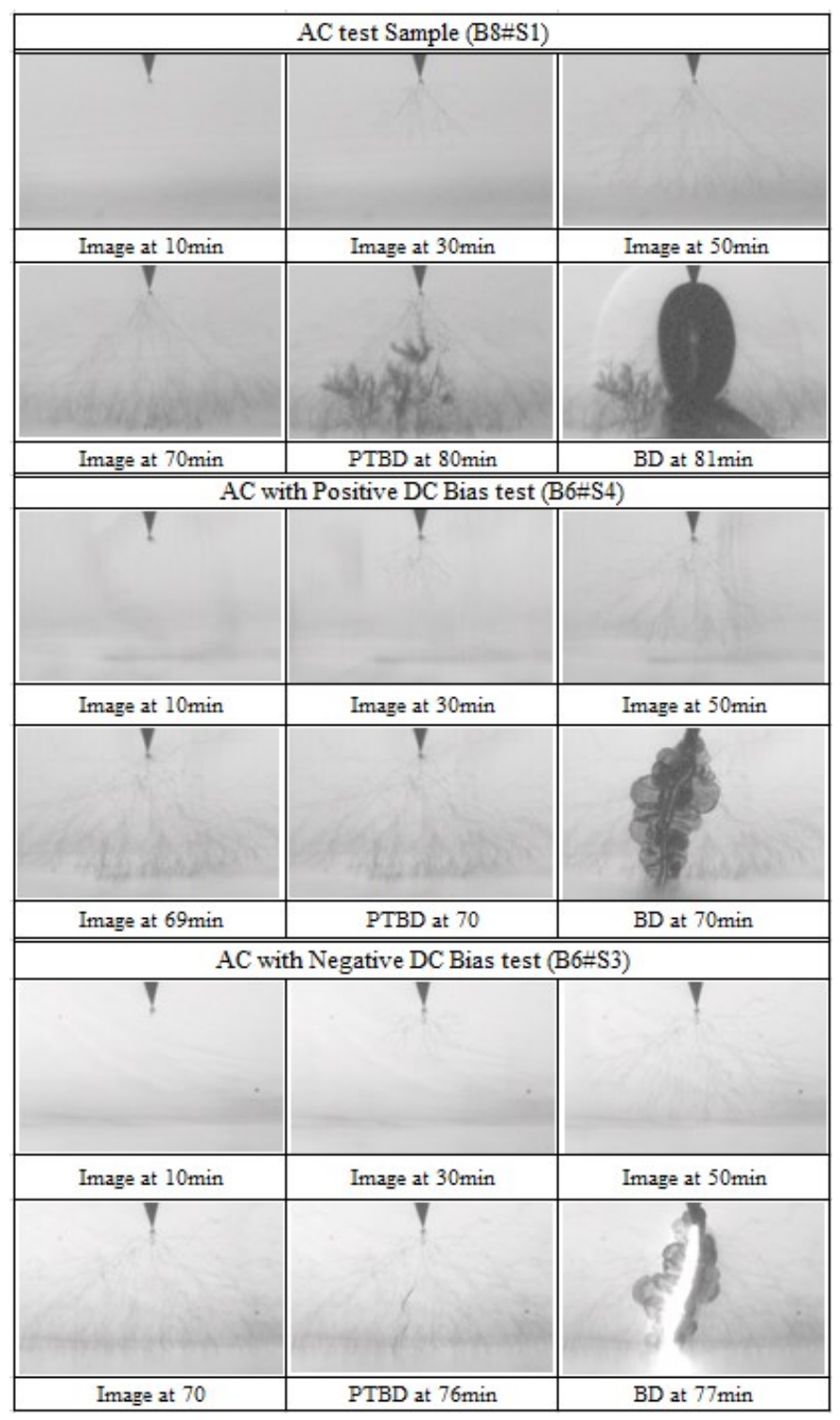

Fig. 6: Comparison of growth characteristics of three samples from the three test types after initiation

That the time to breakdown under positive and negative DC bias tests are shorter than under $\mathrm{AC}$ test reveal that, the rate of tree propagation is driven by the combined effect of $\mathrm{AC}$ and DC components (effective rms value) of the applied waveform and not only the $\mathrm{AC}$ component. This is in agreement with the findings in [13] on tree initiation using superimposed voltages. It is suggested that the longer time to breakdown with negative DC bias compared to with positive bias is due to electric field moderation by homo-space charge at the negative electrode [9$10]$.

In stage 4, the reverse tree growth may be due to the relatively low field under $\mathrm{AC}$ test as compared to the tests with biased fields. Table 1 shows the calculated peak fields (i.e. determined from geometry and voltage alone) at the needle tip are nearly doubled in the DC biased tests. Also for all samples under DC bias tests, it is only the forward moving channels which become dark and widened from the existing fine channels that facilitated path to failure.

\section{CONCLUSIONS}

It is observed that although pure DC stresses generally do not lead directly to rapid tree growth, when combined with $\mathrm{AC}$ stresses they do accelerate tree growth and lead to faster breakdown than if only the AC field was present. The positive DC bias test had a more detrimental effect than the negative bias.

The fourth stage of tree growth identified here, in which a tree grows backwards through the first tree from the plane electrode towards the needle electrode, only occurs at lower test voltage magnitudes. This is not a process seen at higher fields. Reverse trees or trees growing from the planar electrode have been observed previously [14] at 13 to $14 \mathrm{kVrms}$ and in [15] at $15 \mathrm{kV}$ as in this study. If this event is indeed associated with lower voltages, it will impact practical insulation design and require furthers investigation.

\section{ACKNOWLEDGMENT}

The authors are grateful to the RCUK's Energy Programme for the financial support of this work through the Top \& Tail Transformation grant, EP/1031707/1

(http://www.topandtail.org.uk)

\section{REFERENCES}

[1] R. M. Eichhorn, "Treeing in Solid Extruded Electrical Insulation," IEEE Trans. Electr. Insul., vol. EI-12, no. 1, 1977.

[2] J. H. Mason, "Assessing the resistance of polymers to electrical treeing," IEE Proc., vol. 128, no. No. 3, pp. 193-201, 1981.

[3] S. Bamji, "Electrical Trees, Physical Mechanisms and Experimental Techniques," in Wiley Encyclopedia of Electrical and Electronics, J. Webster, Ed. John Wiley \& Sons, 1999, pp. 264-275.

[4] I. Ieda and N. Nawata, "DC Treeing Breakdown Associated with Space Charge Formation in Polyethylene," IEEE Trans. Electr. Insul., vol. EI12, no. $1,1977$.

[5] I. Iddrissu, S. M. Rowland, and A. Tzimas, "The Impact of Interfaces and Space Charge Formation on Breakdown Strength of Epoxy Resin,' 2014, pp. 90-93.

[6] K. P. Padiyar, HVDC Power Transmission Systems: Technology and Systme Interactions. New Delhi, India: Willey \& Sons, 1990.

[7] Y. Li and T. Takada, "Progress in space charge measurement of solid insulating materials in Japan," IEEE Electr. Insul. Mag., vol. 10, no. 5, pp. 16-28, Sep. 1994.

[8] B. Jacobson, B. Wetman, and M. p Bahrman, "Advances in voltage source converter (VSC) technologies," San Fr. Colloq., pp. 1-7, 2012.

[9] J. H. Mason, "Breakdown of solid dielectrics in divergent fields," no. 127 , pp. 254-263, 1955.

[10] E. Kuffel, W. S. Zaengl, and J. Kuffel, High Voltage Engineering Fundamentals, 2nd Editio. Oxford, UK: Butterworth-Heinemann, 2000.

[11] L. A. Dissado and J. C. Fothergil, Electrical Degradation and Breakdown in Polymer. London, U.K.: Perengrinusn Press, 1992.

[12] R. Vogelsang, B. Fruth, T. Farr, and K. Fröhlich, "Detection of electrical tree propagation by partial discharge measurements," Eur. Trans. Electr. Power, vol. 15, no. 3, pp. 271-284, May 2005.

[13] Y. Saito, M. Fukuzawa, and M. Nakamura, "On the mechanism of tree initiation,” IEEE Trans Electrical Insulation., no. 1, pp. 31-34, 1977.

[14] S. Bahadoorsingh, "Asset Management and the Role of Power Quality on Electrical Treeing in Epoxy Resin," University of Manchester, 2009.

[15] D. W. Kitchin and O. S. Pratt, "Treeing in Polyethylene as a Prelude to Breakdown," Trans. Am. Inst. Electr. Eng. Part III Power Appar. Syst., vol. 77 , no. 3 , pp. $180-185,1958$. 